\title{
The transfer of artificial radioelements contained in seaweed to food transformation products (alginates and carrageenans)
}

\author{
D. Maro, C. Rommens ${ }^{1}$, D. Hebert, M. Masson, P. Bouisset ${ }^{2}$, P. Germain and J. Loiseau ${ }^{3}$
}

Institut de Protection et de Sûreté Nucléaire, Département de Protection de l'Environnement, Service d'Études et Recherches Radioécologiques dans les Milieux NATurels, LERFA, 50130 Cherbourg-Octeville, France

'Institut de Protection et de Sûreté Nucléaire, Département de Protection de l'Environnement, Service d'Études et Recherches Radioécologiques dans les Milieux NATurels, LERMC, CE Cadarache, 13108 Saint-Paul-lez-Durance, France

${ }^{2}$ Institut de Protection et de Sûreté Nucléaire, Département de Protection de l'Environnement, Service d'Études et Recherches Radioécologiques dans les Milieux NATurels, LMRE,

Bois des Rames, bâtiment 501, 91400 Orsay, France

${ }^{3}$ DEGUSSA Texturant Systems, 50500 Baupte, France

\begin{abstract}
As part of the work of the Groupe Radioécologie Nord Cotentin (the Nord Cotentin Radioecology Group or GRNC), a study has been carried out of potential routes of exposure associated with the industrial extraction of gelling agent from seaweed harvested on the coastline of the English Channel. The main question was whether the seaweed transformation operations tend to eliminate or concentrate the radioactivity in the consumed products. Work carried out in 1989 showed that the extraction of gelling agents from seaweed results in a significant reduction in the artificial radioactivity present in the raw product for radionuclides such as ${ }^{137} \mathrm{Cs},{ }^{125} \mathrm{Sb}$, ${ }^{106} \mathrm{Ru}-\mathrm{Rh}$, ${ }^{60} \mathrm{Co},{ }^{99} \mathrm{Tc},{ }^{110 \mathrm{~m}} \mathrm{Ag}$, but with the exception of ${ }^{90} \mathrm{Sr}$. However, it seemed important to complete this work by studying transfers of ${ }^{129} \mathrm{I}$, plutonium isotopes $\left({ }^{238,239,}{ }^{240} \mathrm{Pu}\right.$ ), ${ }^{241} \mathrm{Am}$ and ${ }^{244} \mathrm{Cm}$. The seaweed species studied (Laminaria digitata and Chondrus crispus) were collected during February 1999 in the port of Goury, $5 \mathrm{~km}$ from the outlet pipe of the La Hague COGEMA nuclear reprocessing plant. This new study confirms that a significant proportion of the artificial radioactivity present in the initial product is eliminated in the end products, including Iodine, Plutonium, Americium and Curium.
\end{abstract}

\section{INTRODUCTION}

The unusually high incidence of leukemia among young people in the canton of Beaumont-Hague (NW France) from 1978 to 1996, and the link suggested in 1997 with in particular the consumption of sea food products, led the government to ask a commission of experts, the Groupe Radioécologie Nord-Cotentin (the Nord Cotentin Radioecology Group or GRNC) to carry out a thorough radioecological investigation around the La Hague site [1]. As part of the investigations of this working group, the question was raised of the consumption of seaweed-based products as a potential source of exposure of the population to the radioactivity present in harvested seaweed arising from radioactive releases into the sea from nuclear installations in Nord-Cotentin. Seafood products are rarely eaten unprocessed; they undergo transformation of a varying level of sophistication, ranging from simple separation of edible products (the flesh of shellfish, crustaceans and fish) to more complex transformation operations, such as the extraction of gelling agents and thickeners from seaweed (hydrocolloïds). The only factory carrying out such transformation using seaweed harvested near to the La Hague site is the Baupte factory operated by the DEGUSSA company. To provide an answer to the GRNC, a study was set up by IPSN/LERFA (the Institute for Protection and Nuclear Safety, Atlantic seaboard radioecology laboratory) in partnership with SKW Biosystems (the former operator of the Baupte factory) and subsequently with DEGUSSA. The aim of the experiments was to study what happens during the industrial processes to the radionuclides accumulated by the seaweed, and to establish whether the transformation processes applied to the seaweed harvested on the Channel coast tend to eliminate or to concentrate the radioactivity in the consumed products [2] [3].

Work carried out in 1989 [3] showed that the extraction of gelling agents from seaweed results in a significant reduction of the artificial radioactivity present in the raw product $\left({ }^{137} \mathrm{Cs},{ }^{125} \mathrm{Sb},{ }^{106} \mathrm{Ru}-\mathrm{Rh},{ }^{60} \mathrm{Co}\right.$, ${ }^{99} \mathrm{Tc},{ }^{110 \mathrm{~m}} \mathrm{Ag}$ ), with the exception of ${ }^{90} \mathrm{Sr}$. However, it seemed important to complete this work by studying transfers of ${ }^{129} \mathrm{I}$, plutonium isotopes $\left({ }^{238,239,240} \mathrm{Pu}\right.$ ), ${ }^{241} \mathrm{Am}$ and ${ }^{244} \mathrm{Cm}$ from seaweed (Laminaria 
digitata and Chondrus crispus) to the hydrocolloïds produced by the Baupte factory. These hydrocolloïds can be divided into two groups on the basis of their food properties: alginates (alginic acid) and carrageenans (High Milk Reactive (HMR) and satiagum) [4] [5]. The seaweed samples were collected during 1999 in the Nord Cotentin near to the La Hague nuclear reprocessing plant, where the observed artificial radioactivity levels are the highest in the Channel. This region, like Brittany, has a tradition of harvesting seaweed for the gelling agent industry.

\section{MATERIALS AND METHODS}

\subsection{Sampling methodology}

Brown seaweed (Laminaria digitata) and red seaweed (Chondrus crispus) were collected during February 1999 in the port of Goury, $5 \mathrm{~km}$ from the outlet pipe of the La Hague nuclear reprocessing plant (figure 1).

The two batches of seaweed (50 kg of Laminaria digitata and $100 \mathrm{~kg}$ of Chondrus crispus) were taken to the DEGUSSA factory at Baupte, in the middle of the La Manche département (France), for processing using the standard industrial processes in order to extract the alginates (alginic acid) from Laminaria digitata and the carrageenans (HMR and satiagum) from Chondrus crispus [4] [5].

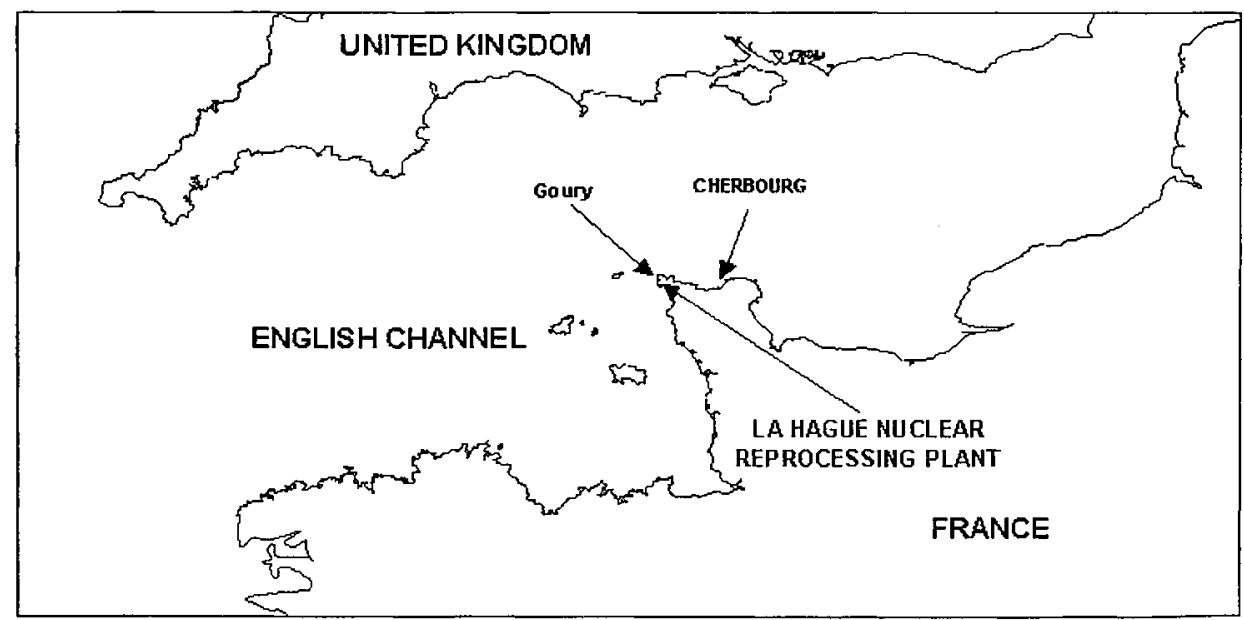

Figure 1: Sampling Laminaria digitata and Chondrus crispus at the port of Goury

\subsection{Alginate extraction}

The Laminaria digitata are shredded and then demineralized by leaching in sulfuric acid (figure 2). They are then ground and macerated in an alkaline medium (sodium carbonate) in order to neutralize the alginic acid and to render them soluble in the form of the corresponding salt. The insoluble compounds (debris and cellulose) are then removed by floatation or filtration. Next, the alginic acid is precipitated by adding a mineral acid (sulfuric acid) to the clarified alginate solution. Depending on the type of alginate desired, the alginic acid is neutralized using sodium, potassium or ammonium salt to form an alginate which can then be used as a gelling agent or a thickener in the food industry. 


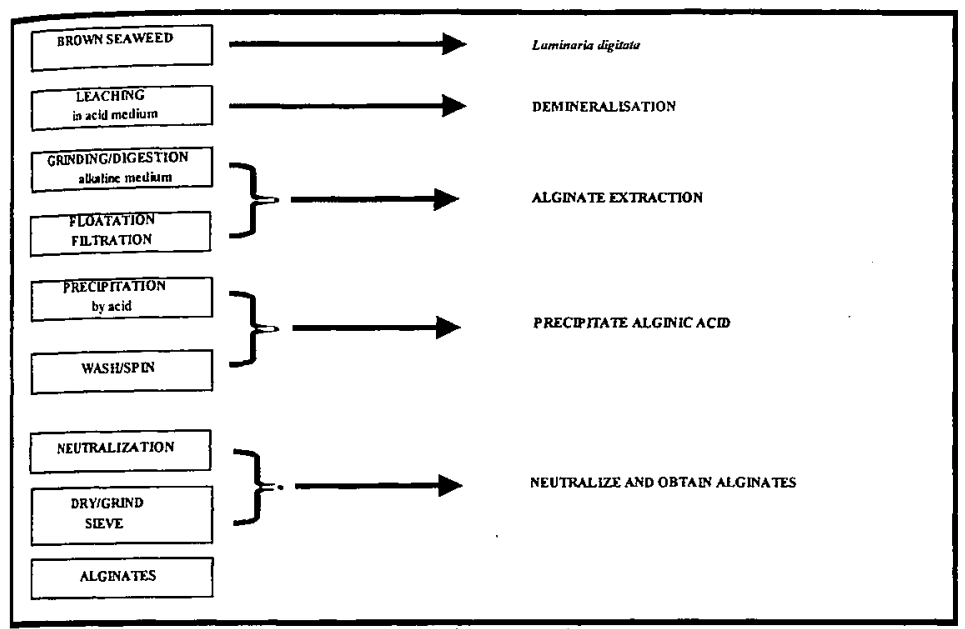

Figure 2: Process for extracting alginic acid and alginates

\subsection{Carrageenan extraction}

After washing, the Chondrus crispus are macerated in hot water (figure 3), then ground and cooked in an alkaline medium (lime). Two concentrations of alkaline solution are used to obtain the two types of end product, HMR and satiagum. HMR is a gelling agent, while satiagum is used as a thickener. After filtering to eliminate insoluble impurities, the hydrocolloïds obtained are precipitated in alcohol. The precipitated carrageenans are then spin-dried, washed in alcohol, pressed, dried, ground and sieved. Carrageenans are polysaccharides which are used as texturizing agents in applications that depend on their rheological properties, mainly in food products and especially dairy products.

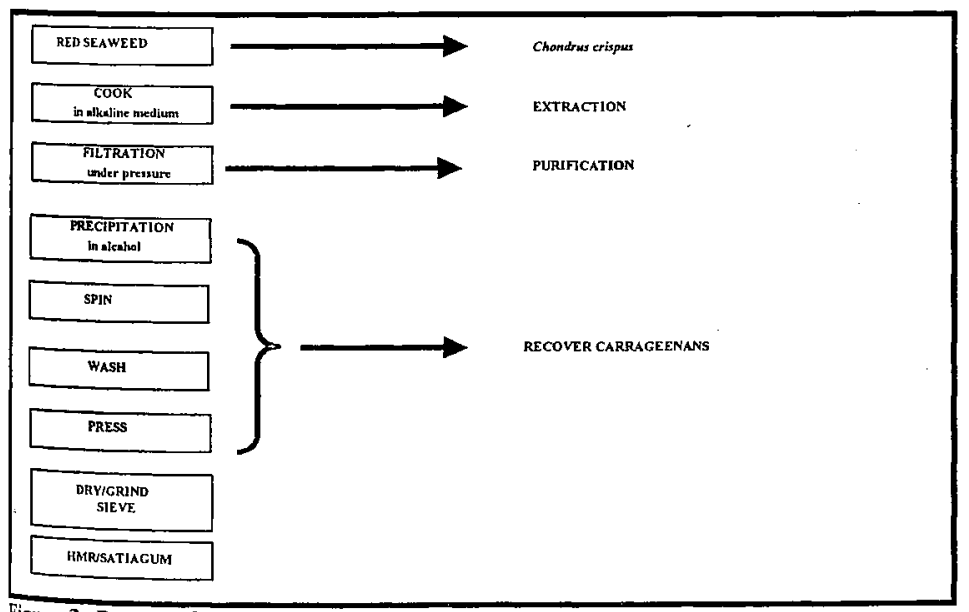

Figure 3: Process for extracting carrageenans

\subsection{Radionuclide measurements}

The sampled seaweeds were dried at $60^{\circ} \mathrm{C}$ to constant weight, then finely ground. The dried seaweed and the extraction products (dry powder) were placed in $350 \mathrm{ml}$ measurement containers. These samples were analyzed using gamma spectrometry by the Laboratoire de Métrologie de la Radioactivité de l'Environnement (LMRE) at the Institute for Protection and Nuclear Safety. 
The ${ }^{99} \mathrm{Tc}$ and ${ }^{129} \mathrm{I}$ doses were measured using dry powders after radiochemical extraction. The radiochemistry and the physical measurements (bêta count and X-ray spectrometry) were carried out by LERFA and by LMRE respectively.

The ${ }^{238} \mathrm{Pu},{ }^{239,240} \mathrm{Pu},{ }^{241} \mathrm{Am}$ and ${ }^{244} \mathrm{Cm}$ measurements were carried out after calcination and radiochemistry by the LMRE.

\section{RESULTS AND DISCUSSION}

The radionuclide concentrations in the seaweeds and in the hydrocolloids (alginic acid, HMR and satiagum) for 1989 and 1999 are given in tables 1 and 2 respectively.

Table 1: Radionuclide concentration (Bq. $\mathrm{kg}^{-1}$ dry weight) in seaweed and hydrocolloïds in 1989 [3]: LD = Limit of Detection (results $\pm 2 \sigma$ )

\begin{tabular}{|c|c|c|c|c|c|c|c|c|}
\hline 1989 & ${ }^{99} \mathrm{Tc}$ & ${ }^{114} \mathrm{Ru}-\mathrm{Rh}$ & ${ }^{60} \mathrm{Co}$ & ${ }^{137} \mathrm{Cs}$ & ${ }^{125} \mathrm{Sb}$ & ${ }^{111 \mathrm{~m}} \mathrm{Ag}$ & ${ }^{58} \mathrm{Co}$ & ${ }^{911} \mathrm{Sr}$ \\
\hline Laminaria digitata & $493 \pm 98$ & $156 \pm 15$ & $9.6 \pm 1.9$ & $3.0 \pm 1.5$ & $1.5 \pm 0.7$ & $3.0 \pm 1.5$ & $0.6 \pm 0.3$ & $9.0 \pm 1.8$ \\
Alginic acid & $29 \pm 6$ & $31 \pm 15$ & $<\mathrm{LD}$ & $<\mathrm{LD}$ & $<\mathrm{LD}$ & $<\mathrm{LD}$ & $<\mathrm{LD}$ & $15 \pm 3$ \\
Chondrus crispus & $<\mathrm{LD}$ & $341 \pm 34$ & $31 \pm 3$ & $1.4 \pm 0.7$ & $2 \pm 1$ & $1.0 \pm 0.5$ & $0.5 \pm 0.3$ & $<\mathrm{LD}$ \\
HMR & $<\mathrm{LD}$ & $47 \pm 24$ & $2.2 \pm 1.1$ & $<\mathrm{LD}$ & $<\mathrm{LD}$ & $<\mathrm{LD}$ & $<\mathrm{LD}$ & $<\mathrm{LD}$ \\
Satiagum & $<\mathrm{LD}$ & $45 \pm 22$ & $4.7 \pm 2.4$ & $1.2 \pm 0.6$ & $<\mathrm{LD}$ & $<\mathrm{LD}$ & $<\mathrm{LD}$ & $<\mathrm{LD}$ \\
\hline
\end{tabular}

Table 2: Radionuclide concentration (Bq. $\mathrm{kg}^{-1} \mathrm{dry}$ weight) in seaweed and hydrocolloïds in 1999: $\mathrm{LD}=\mathrm{Limit}$ of Detection (results $\pm 2 \sigma$ )

\begin{tabular}{|c|c|c|c|c|c|c|c|c|c|}
\hline 1999 & ${ }^{99} \mathrm{Tc}$ & ${ }^{1+k 6} \mathbf{R u}-\mathbf{R b}$ & ${ }^{611} \mathrm{Co}$ & ${ }^{137} \mathrm{Cs}$ & ${ }^{12 \%} \mathrm{I}$ & ${ }^{23 H} \mathrm{Pu}$ & ${ }^{239,2+10} \mathbf{P u}$ & ${ }^{2+1} \mathrm{Am}$ & ${ }^{24+4} \mathrm{Cm}$ \\
\hline Laminaria digitato & $39.3 \pm 3.9$ & $12.0 \pm 5.6$ & $<L D$ & $0.7 \pm 0.3$ & $426.5 \pm 50.5$ & $5.910^{-2} \pm 3.310^{-3}$ & $8.510^{-2} \pm 4.1 \quad 10^{-7}$ & $-35.910^{-2} \pm 4.410^{-3}$ & $-3\left(1.210^{-2} \pm 1.810^{0}\right.$ \\
\hline Alginic acid & $5.6 \pm 1.2$ & $\angle L D$ & $<L D$ & $\angle L D$ & $<L D$ & $1.310^{-3} \pm 3.310^{-1}$ & $+2.110^{-3} \pm 3.910^{-1}$ & $7.510^{-4} \pm 3.610^{-4}$ & $+<\mathrm{LD}$ \\
\hline Chondrus crispus & $4.4 \pm I .1$ & $26.4 \pm 2.8$ & $3.1 \pm 0.2$ & $0.3 \pm 0.1$ & $46.7 \pm 7.1$ & $1.310^{-1} \pm 1.110^{-2}$ & $=1.810^{-1} \pm 1.310^{-2}$ & $-23.410^{-1} \pm 3.010^{-2}$ & $-28.610^{-2} \pm 1.110^{-2}$ \\
\hline HMR & $2.1 \pm 1.0$ & $<L D$ & $0.4 \pm 0.2$ & $<\mathrm{LD}$ & $4.8 \pm 0.9$ & $4.710^{-3} \pm 2.210^{-3}$ & $3.610^{-3} \pm 3.110^{-3}$ & $-3.3 .210^{-3} \pm 1.510^{-3}$ & $-31.210^{-3} \pm 9.110^{-1}$ \\
\hline Satiagum & $2.0 \pm 1.0$ & $6.8 \pm 1.8$ & $1 \pm 0.1$ & $0.2 \pm 0.1$ & $4.1 \pm 0.8$ & $4.810^{-2} \pm 6.710^{-3}$ & $35.610^{-2} \pm 7.410^{-1}$ & $8.510^{-2} \pm 1.110^{-2}$ & $.21 .910^{-2} \pm 4.710^{-3}$ \\
\hline
\end{tabular}

Because of the reduction in liquid release into the sea from the La Hague nuclear reprocessing plant, the number and concentration of gamma source radionuclides in seaweed $\left({ }^{137} \mathrm{Cs},{ }^{125} \mathrm{Sb},{ }^{106} \mathrm{Ru}-\mathrm{Rh}\right.$, ${ }^{60} \mathrm{C}$, ${ }^{58} \mathrm{Co},{ }^{99} \mathrm{Tc},{ }^{110 \mathrm{~m}} \mathrm{Ag}$ ) have both clearly reduced over the period 1989 to 1999 . The ${ }^{90} \mathrm{Sr}$ detected in 1989 in Laminaria digitata and in alginic acid is no longer present in 1999 . However, ${ }^{129} \mathrm{I}$ releases have increased by a factor of seven from 1989 to 1999 and was found to be present in both types of seaweed but was only found in the carrageenans. When the alginates are extracted, the precipitation of alginic acid by adding a mineral acid tends to help eliminate iodine from the final product and so may explain why no measurable amount of iodine is found. The ${ }^{238} \mathrm{Pu},{ }^{239,240} \mathrm{Pu},{ }^{241} \mathrm{Am}$ and ${ }^{244} \mathrm{Cm}$ radionuclides are found in all the samples (both seaweed and hydrocolloïds) except for ${ }^{244} \mathrm{Cm}$ which is not found in alginic acid.

All the results show (tables 3 and 4) that the extraction of gelling agent products from brown and red seaweed results in a significant reduction in radioactivity (except for ${ }^{90} \mathrm{Sr}$ ). This result includes the new radionuclides studied $\left({ }^{129} \mathrm{I},{ }^{238} \mathrm{Pu},{ }^{239,240} \mathrm{Pu},{ }^{241} \mathrm{Am}\right.$ and $\left.{ }^{244} \mathrm{Cm}\right)$ and concur with the study carried out by Masson et al. in 1989 [3]. 
The 1999 measurements show that for ${ }^{106} \mathrm{Ru}-\mathrm{Rh},{ }^{60} \mathrm{Co},{ }^{129} \mathrm{I},{ }^{238} \mathrm{Pu},{ }^{239,240} \mathrm{Pu},{ }^{241} \mathrm{Am}$ and ${ }^{244} \mathrm{Cm}$, more than $90 \%$ of the initial radioactivity is eliminated by the gelling agent extraction processes. The ${ }^{137} \mathrm{Cs}$ radionuclide is more than $75 \%$ eliminated (1989 and 1999 measurements).

Because of the reduction in ${ }^{90} \mathrm{Sr}$ release from the La Hague nuclear reprocessing plant, this radioelement could not be detected in 1999 so it was not possible to confirm the 1989 results (which indicated that $56 \%$ of the ${ }^{90} \mathrm{Sr}$ remained in the final product). However, alginates are known for their ability to fix strontium, a property which is used to reduce intestinal absorption of ${ }^{90} \mathrm{Sr}$ in the event of contamination [6].

Table 3: Fraction of radioactivity (\%) in the final product (hydrocolloïds) relative to the initial product (seaweed), sampled in 1989: $\mathrm{LD}=$ Limit of Detection, $\mathrm{NM}=$ Not Measured

\begin{tabular}{|c|c|c|c|c|c|c|c|c|c|c|c|c|}
\hline 1989 & $\begin{array}{c}\text { Hydrocolloid extraction } \\
\text { yield (\%) }\end{array}$ & ${ }^{94} \mathrm{Tc}$ & ${ }^{116} \mathrm{Ru}-\mathrm{Rh}$ & ${ }^{610} \mathrm{Co}$ & ${ }^{137} \mathrm{Cs}$ & ${ }^{129} \mathrm{I}$ & ${ }^{94} \mathrm{Sr}$ & ${ }^{236} \mathrm{Pu}$ & ${ }^{133,2+11} \mathrm{Pu}$ & ${ }^{2+1} \mathrm{Am}$ & ${ }^{2+4} \mathrm{Cm}$ \\
\hline Alginic acid & 3.7 & 2.0 & 6.6 & $<\mathrm{LD}$ & $<\mathrm{LD}$ & $\mathrm{NM}$ & 56.0 & $\mathrm{NM}$ & $\mathrm{NM}$ & $\mathrm{NM}$ & $\mathrm{NM}$ \\
HMR & 10.3 & $\mathrm{LD}$ & 3.6 & 1.8 & $<\mathrm{LD}$ & $\mathrm{NM}$ & $\mathrm{NM}$ & $\mathrm{NM}$ & $\mathrm{NM}$ & $\mathrm{NM}$ & $\mathrm{NM}$ \\
Satiagum & 7.8 & $<\mathrm{LD}$ & 3.7 & 4.3 & 24.1 & $\mathrm{NM}$ & $\mathrm{NM}$ & $\mathrm{NM}$ & $\mathrm{NM}$ & $\mathrm{NM}$ & $\mathrm{NM}$ \\
\hline
\end{tabular}

Table 4: Fraction of radioactivity (\%) in the final product (hydrocolloïds) relative to the initial product (seaweed), sampled in 1999: $L D=$ Limit of Detection, NM = Not Measured

\begin{tabular}{|c|c|c|c|c|c|c|c|c|c|c|c|}
\hline 1999 & $\begin{array}{c}\text { Hydrocolfoid extraction } \\
\text { yield (\%) }\end{array}$ & ${ }^{99} \mathrm{Te}$ & ${ }^{1+6} \mathrm{Ru}-\mathrm{Rh}$ & ${ }^{60} \mathrm{Co}$ & ${ }^{137} \mathrm{Cs}$ & ${ }^{129} \mathbf{I}$ & ${ }^{50} \mathrm{Sr}$ & ${ }^{238} \mathrm{Pu}$ & ${ }^{239,2+0} \mathrm{Pu}$ & ${ }^{241} \mathrm{Am}$ & ${ }^{241} \mathrm{Cm}$ \\
\hline Alginic acid & 4.7 & 4.5 & $<\mathrm{LD}$ & $<\mathrm{LD}$ & $<\mathrm{LD}$ & $<\mathrm{LD}$ & $<\mathrm{LD}$ & 0.7 & 0.8 & 0.4 & $<\mathrm{LD}$ \\
HMR & 11.4 & 16.7 & $<\mathrm{LD}$ & 4.6 & $<\mathrm{LD}$ & 3.6 & $<\mathrm{LD}$ & 1.2 & 1.5 & 0.3 & 0.5 \\
Satiagum & 7.5 & 10.4 & 6.0 & 7.5 & 15.5 & 2.0 & $<\mathrm{LD}$ & 8.4 & 7.4 & 5.8 & 5.1 \\
\hline
\end{tabular}

It is important to be aware that the final product (alginates or carrageenans) is generally used at a concentration by weight which is well below $1 \%$ in the various food preparations (such as sauces, creams, and dairy products). Over the two measurement surveys, the maximum content of radionuclides from seaweed which is likely to be incorporated into products for human consumption (radioactivity in the food preparation relative to the initial product) is $5.610^{-3}$ for ${ }^{90} \mathrm{Sr}, 2.410^{-3}$ for ${ }^{137} \mathrm{Cs}, 1.710^{-3}$ for ${ }^{99} \mathrm{Tc}, 8.4$ $10^{-4}$ for ${ }^{106} \mathrm{Ru}-\mathrm{Rh},{ }^{60} \mathrm{Co},{ }^{238} \mathrm{Pu},{ }^{239,240} \mathrm{Pu},{ }^{241} \mathrm{Am},{ }^{244} \mathrm{Cm}$ and $3.610^{-4}$ for ${ }^{129} \mathrm{~T}$.

Furthermore, the transformation industries obtain their supply from a sufficiently diverse range of sources (Normandy, Brittany, etc.) for the artificial radioactivity to be further diluted during manufacture. In the case of the Baupte factory, the Chondrus crispus sampled in the Nord Cotentin accounts for $15 \%$ of its French supply (the rest comes from Brittany), which in turn represents less than $5 \%$ of the total supply. In contrast, the supply of Laminaria used for French alginates comes exclusively from Brittany [3] [4].

\section{CONCLUSION}

This work has been carried out in response to questions raised by the GRNC group concerning transfers of radioelements from seaweed to humans [1]. For all the radionuclides measured, except for ${ }^{90} \mathrm{Sr}$, this study shows that there is a significant reduction in the concentration of artificial radioactivity between the initial product (Laminaria digitata or Chondrus crispus) and the final products (alginates or carrageenans). This reduction, combined with the dilution phenomena which take effect at different stages in the food industry transformation chain (diversity of sources and use of gelling agents in very small quantities in the products for human consumption) ensures that the levels of radioactivity resulting from this practice contained in the products sold for consumption are very low. This general conclusion concurs with the study carried out by Masson et al. [3] and also applies for the new radioelements 
studied, ${ }^{129} \mathrm{I},{ }^{238,239,240} \mathrm{Pu},{ }^{241} \mathrm{Am}$ and ${ }^{244} \mathrm{Cm}$. Finally, as part of the same study, measurements are still under way to evaluate transfers of ${ }^{3} \mathrm{H}$ and ${ }^{14} \mathrm{C}$ to hydrocolloids and to assess the radioactivity levels of by. products of the industrial processes.

\section{Acknowledgements}

The authors would like to thank DEGUSSA Texturant Systems (Baupte factory) for having enabled this study to take place by carrying out the alginate and carrageenan extractions.

\section{References}

[1]. Groupe Radioécologie Nord Cotentin (GRNC), Estimation des niveaux d'exposition aux rayonnements ionisants et des risques de leucémies associés de populations du Nord-Cotentin, summary report, July 1999, $358 \mathrm{p}$.

[2]. Pomarola M. H., Augustin C., Recherche de l'apport éventuel en radioéléments de certains produits d'addition : émulsifiants, stabilisants, épaississants, gélifiants, tirés des algues marines, Internal report by the Laboratoire central de recherches et d'analyses (Massy, France), $23 \mathrm{p}$.

[3]. Masson M., Germain P., Eyssaultier B., Grauby A., Evolution de la radioactivité de produits marins des côtes de la Manche au cours de la transformation agro-alimentaire (algues) ou au cours de la préparation culinaire (moules), Radioactivity transfer during food processing and culinary preparation, Cadarache France 18-21 September 1989, pp. 457-468.

[4]. HYDROCOLLOÏDES, published by SKW-Biosystems (1999), pp. 17-30.

[5]. Pagny O., Extractions pilote sur Chondrus et Laminaires de différentes provenances, Sanofi Bioindustries report OP/ML 352.89, July 1989, 7 p.

[6]. Tanaka Y., Stara J.F., Algal polysaccharides: their potential use to prevent metal poisoning, in Marine algae in pharmaceutical science, Hoppe H.A., Levring T., Tanaka Y. (Eds) W de Gruyter, Berlin 1979, pp. $525-543$. 